\title{
A QUESTÃO CURDA NA GUERRA DA SÍRIA: DINÂMICAS INTERNAS E IMPACTOS REGIONAIS ${ }^{1}$
}

Reginaldo Mattar Nasser ${ }^{\mathrm{a}}$

aé professor do Departamento de Relações Internacionais da Pontifícia Universidade Católica de São Paulo (PUC-SP). São Paulo,SP, Brasil.E-mail:<reginaldonasser@gmail.com>

Orcid: 0000-0001-5674-4197

\section{Willian Moraes Roberto ${ }^{b}$}

'é mestre em relações internacionais pelo Programa de Pós-Graduação San Tiago Dantas (Unesp-Unicamp-PUC-SP). São Paulo,SP, Brasil.E-mail:<willianmroberto@gmail.com>

Orcid: 0000-0003-1686-4172

http://dx.doi.org/10.1590/0102-219246/106

\section{Introdução}

As questões políticas envolvendo a região do Oriente Médio são analisadas, na literatura de relações internacionais, predominantemente pela perspectiva do realismo em suas diferentes vertentes, de modo que os Estados aparecem como os atores determinantes nos conflitos. Porém, é preciso destacar que as questões transnacionais sempre estiveram presentes na história do Oriente Médio, seja pela difusão do nacionalismo árabe, seja pelo islamismo e suas conexões locais e globais (Halliday, 2005). Tais fenômenos voltaram a ocupar posição de destaque nas dinâmicas regionais após a Primavera Árabe, sobretudo na guerra civil da Síria, devido ao fortalecimento progressivo do Estado Islâmico (EI), de um lado, e as ações dos grupos curdos, de outro.

Pela primeira vez na história desde a criação dos Estados modernos da Turquia, Síria e Iraque, os curdos começaram a impactar significativamente a ação política das potências

\footnotetext{
1 Este texto baseou-se em informações contidas na dissertação de mestrado As mudanças na política externa contemporânea da Turquia: as respostas diante das revoltas árabes pós-2011 (Roberto, 2018).
} 
regionais e globais. Com o estabelecimento em 2005 do Governo Regional do Curdistão (GRG), no Iraque, e uma presença mais ativa nas eleições turcas nos últimos anos, os curdos passaram a ganhar mais visibilidade internacional.

Mas a denominada "questão curda" se destacou no cenário geopolítico do Oriente Médio em 2012, quando o Partido da União Democrática (PYD, na sigla original), sírio-curdo, assumiu o controle de três áreas de maioria curda ao longo da fronteira norte da Síria.

Há uma ampla gama de atores envolvidos na guerra civil na Síria, desde potências mundiais e Estados regionais até uma série de redes de combatentes não estatais. Conflitos internos e guerras civis, em geral, tendem a se espalhar pela região devido à forte conexão entre grupos políticos de diferentes Estados; no caso em questão, há forte envolvimento de Iraque, Síria e Turquia devido ao enfrentamento ou aliança desses governos com organizações não estatais (Dal, 2017).

220 O controle territorial e o experimento político de um governo curdo no norte da Síria, que teve início em 2012, passou a ser fator decisivo para os cálculos estratégicos dos Estados Unidos (EUA), Síria, Iraque, Irã e Turquia. Assim, apesar de a questão curda sempre ter estado presente na política externa turca em sua relação com os países vizinhos, que também possuem população curda, suas interações transnacionais não eram levadas tão a sério pelo governo quanto o são atualmente (Halhalli, 2015b).

Por conta do impacto causado pelas ações estratégicas das grandes potências, a ação política dos curdos, em geral, e dos curdos sírios, em particular, vem demandando, cada vez mais, novas investigações para sua compreensão.

Antes da guerra civil na Síria, os curdos desse país raramente apareciam nas pesquisas acadêmicas (Tejel, 2009). São cerca de 1,5 milhão de pessoas, o que representa quase $7 \%$ da população total do país. Trata-se do menor número, tanto em termos absolutos quanto relativos, dos quatro 
países (Síria, Iraque, Turquia e Irã) com população curda no Oriente Médio (Capitalizing..., 2016). Além disso, os curdos sírios foram considerados na literatura especializada, na maior parte, como um grupo que poderia ser facilmente assimilado a um ambiente de maioria árabe, desempenhando apenas um papel marginal na evolução política da Síria, em contraste com outras "minorias", como os drusos e os alauítas. Assim, nas raras vezes em que apareciam "demandas de identidade", essas eram interpretadas apenas como manobras táticas da elite curda devido à perda de poder diante das transformações socioeconômicas do país (Natali, 2005). Mesmo entre aqueles que passaram a olhar com mais atenção a movimentação dos curdos na Síria nos últimos anos, há uma tendência a enquadrar a questão como parte um grande movimento unificado e homogêneo (The Kurds'..., 2017).

Assim, entendemos que para analisar a questão curda é preciso compreender a forma pela qual essa população se organiza politicamente na região, levando em consideração suas particularidades, e, principalmente, as tensões políticas e disputas internas de seu movimento, que envolvem tanto os grupos sírios quanto os turcos e iraquianos. $\mathrm{O}$ fato de esses movimentos terem sido representados por diferentes organizações e razões em variados contextos históricos nos alerta para interpretações equivocadas que se referem a um único movimento nacionalista curdo.

As distintas organizações curdas se desenvolveram em momentos distintos, com lógicas, objetivos e projetos variados (Brubaker, 2004). Segundo a perspectiva de group-making (Brubaker, 2004), durante o processo em que grupos são constituídos há sempre uma ideologia política que embasa a estrutura na qual os membros são organizados, interagem e concebem seu papel em relação aos outros. Portanto, para analisar os processos de formação de coletivos e o papel que desempenham nas ações políticas, é importante levar em consideração como as ideologias políticas subjacentes 
influenciam as interações entre as organizações nacionalistas curdas e os Estados (Wuthrich, 2018).

Nesse sentido, nosso objetivo é contribuir para uma compreensão mais adequada da questão curda e de seus desdobramentos, buscando explorar a complexidade das dinâmicas envolvendo os grupos curdos em geral e, mais especificamente, na guerra civil da Síria. Trata-se de compreender a forma como o experimento curdo se organiza politicamente na região, e, sobretudo, quais são as tensões políticas e disputas internas ao movimento, que envolvem tanto os grupos sírios quanto os turcos e iraquianos. Questiona-se, assim, a narrativa predominante que analisa as ações dos curdos como se fossem um único movimento.

\section{O histórico da questão curda na Síria e a obtenção da autonomia pelo PYD}

Ao longo dos anos 1960 e 1970, os governos sírio e ira222 quiano empreenderam uma política de "arabização" das regiões de população curda. Na Síria, por exemplo, as terras férteis foram transformadas em propriedade pública e houve incentivo à migração de populações árabes. Com a consequente perda de suas propriedades rurais, os curdos foram obrigados a se deslocar, e um "cinturão árabe" se formou nas províncias do norte do país. Além disso, tanto a língua quanto quaisquer outros tipos de manifestações culturais curdas foram classificadas como "ameaças" à integridade territorial da Síria (Tejel, 2009).

A situação política para os curdos sírios alterou-se somente durante o período entre 1980 e 1990, quando o governo de Hafez al-Assad passou a se utilizar da questão curda como forma de pressionar o governo da Turquia. Na época, as relações turco-sírias encontravam-se deterioradas devido a disputas territoriais envolvendo a província turca de Hatay, reivindicada por Damasco; ao fortalecimento dos laços militares entre o Estado turco e Israel; e à construção de uma enorme represa, 
em 1983, por parte da Turquia, no rio Eufrates, que diminuía o volume de água que corria em direção à Síria. Além disso, desde 1984 o governo turco vinha enfrentando um conflito com a guerrilha do Partido dos Trabalhadores do Curdistão (PKK, na sigla original), que exigia a independência da região curda de seu território. Hafez al-Assad aproveitou-se do problema interno da Turquia e passou a facilitar o estabelecimento de bases do PKK turco no território curdo da Síria. Em troca dessa concessão do governo de Assad, o movimento curdo se comprometeu a não fazer novas demandas em relação ao território sírio, que serviria apenas como base de lançamento de operações contra a Turquia (Tejel, 2009).

Na década de 1990, o PKK começou a usar suas bases na Síria e, dessa forma, criou laços com a comunidade curda local. Seu líder, Abdullah Öcalan, residia no norte do território sírio, de onde comandava a insurgência contra a Turquia. Somente em 1998, quando o governo turco ameaçou intervir militarmente na Síria, Damasco obrigou o PKK a sair de seu território, passando novamente, então, a reprimir o movimento nacional curdo. Graças às relações criadas durante esse período, em 2003 o PKK estabeleceu clandestinamente o PYD, braço político sírio do grupo. Em 2004, um levante curdo ocorreu no norte da Síria, organizado pelo PYD, que teve como consequência a criação de grupos armados, as Unidades de Proteção Popular (YPG, na sigla original) (International Crisis Group, 2013).

A despeito da prisão de diversos membros e de o partido ter sido oficialmente banido em 1998, o PYD continuou se organizando no norte da Síria, principalmente por meio da criação de Comitês Locais Populares, responsáveis por atividades específicas nas áreas curdas. Os líderes do PYD, entretanto, fugiram para o norte do Iraque, que era dominado pelo GRC desde a derrubada do governo de Saddam Hussein pelas forças dos Estados Unidos. É importante destacar que a criação do GRC no Iraque serviu de base para 
abrigar tanto a liderança do PYD, sobretudo seu líder Salih Muslim, solto de uma prisão na Síria em 2010, quanto os guerrilheiros do PKK turco, que seguiam com suas bases nas montanhas de Qandil, no norte do GRC (Barfi, 2016; International Crisis Group, 2013).

Em 2007, os Comitês Locais Populares do PYD se organizaram sob a direção do Comitê de Coordenação Central do partido, que continuava, de maneira clandestina, difundindo suas ideias de autogoverno no território sírio (International Crisis Group, 2013). Quando, em 2011, teve início o levante popular na Síria, a população curda e o PYD se viram diante de um desafio e uma oportunidade. De um lado, aumentava a repressão contra a insurgência, mas, de outro, o enfraquecimento do governo central poderia favorecer o pleito curdo para maior autonomia local e, portanto, aparecia como oportunidade para a causa curda (Lowe, 2016).

Com o objetivo de impedir que as minorias étnicas 224 engrossassem as fileiras da oposição ao regime, o governo sírio flexibilizou as regras de concessão de cidadania aos curdos, que sempre tiveram negada sua identidade como sírios. No final de 2011, vários prisioneiros políticos curdos do PYD foram libertados das prisões do país, retornando ao norte da Síria e, desde então, diversos outros curdos sírios que se encontravam no Iraque treinando com o PKK se integraram às fileiras das YPG (International Crisis Group, 2013).

A revolta contra o governo sírio, no entanto, não foi explorada na região curda apenas pelo PYD. Em outubro de 2011 foi constituído um outro partido local de oposição, o denominado Conselho Nacional Curdo (CNC). Essa divisão no movimento curdo sírio, na verdade, passou a refletir a polarização que se construiu entre o GRC no Iraque e o PKK turco (Lowe, 2016).

O PKK, com seu líder Öcalan preso na Turquia e sua força militar espalhada nas montanhas do Iraque e em bases encobertas no território turco, continuava a sustentar a ação de guerrilha, ainda que objetivasse demandar autonomia 
política para a região curda na Turquia - e não mais reivindicar independência, como era sua agenda nos anos 1990. Nesse sentido, o PKK ainda representava um caminho de enfrentamento e colisão com o governo turco.

Do outro lado, o GRC no Iraque, representado pelo presidente Massoud Barzani, traçou gradualmente uma estratégia diferente em relação aos governos turco e iraquiano. Como o GRC já se consolidara como entidade com autonomia relativa na federação iraquiana, Barzani se aproveitou de uma postura mais pragmática da Turquia para obter recursos. Ainda em 2009, o governo Erdo an investiu na região do Curdistão, principalmente no setor petrolífero e, em troca, o GRC consentiu que a Turquia realizasse ataques aéreos contra o PKK na região de Qandil, no norte do Iraque. De fato, investimentos turcos foram responsáveis pela criação de um oleoduto que liga os campos petrolíferos no Curdistão e o porto turco de Ceyhan - empreendimento que garantiu a exportação de cerca de 600 mil barris de petróleo/dia ao GRC de Barzani (Capitalizing..., 2016). Desse modo, enquanto o PKK adotava uma postura de confronto, o GRC de Barzani optava por laços de interdependência energética com a Turquia em troca de colaborar com seu governo para conter a militância do PKK e permitir ataques turcos contra esse grupo.

Nesse contexto, o fortalecimento do PYD na Síria poderia fortalecer o PKK na região. Diante dessa perspectiva, que já era vista com preocupação pelo governo turco, Barzani propôs, em outubro de 2011, com incentivo de Ancara, a criação de um outro grupo no norte da Síria: o CNC, composto por 17 facções políticas curdas que não faziam parte do PYD (International Crisis Group, 2013).

Um dos principais trunfos do CNC era seu apoio internacional, pois o fato de ser reconhecido e apoiado pelo GRC de Barzani garantiu que o próprio governo turco dialogasse com o grupo. Em agosto de 2012, o então ministro das relações exteriores da Turquia, Ahmet Davuto lu, encontrou-se 
com representantes do CNC em Erbil, capital do Curdistão, tendo sido acompanhado por membros do Conselho Nacional Sírio, principal órgão da oposição ao regime em Damasco na época e que tinha apoio de Ancara. Na mesma ocasião, Davuto lu negou-se a se encontrar com representantes do PYD devido às suas ligações com o PKK turco. Ou seja, o governo turco parecia indicar que reconheceria o CNC como parte da oposição a Bashar al-Assad, atual presidente da Síria, mas não o PYD (International Crisis Group, 2013).

Mesmo contando com certa legitimidade internacional, o CNC não tinha a base de apoio popular que o PYD criara no norte da Síria e muito menos um corpo político unificado e coeso. Dessa forma, o PYD cresceu no território sírio como o CNC jamais conseguiu (International Crisis Group, 2013). Barzani chegou a tentar forjar uma aliança entre o PYD e o CNC ao longo de 2012, tentando afastar o PYD de seus laços tradicionais com o PKK e aproximá-lo do GRC. A principal 226 tentativa do líder envolvia um acordo em que o PYD abriria mão do monopólio sobre a segurança na região curda da Síria e passaria a formar um Comitê de Segurança Conjunto. Segundo essa proposta, a segurança no norte sírio ficaria sob responsabilidade não apenas das YPG, mas também de curdos sírios treinados pelas unidades do GRC no Iraque - as Peshmerga iraquianas. Entretanto, o PYD não apenas se recusou a participar dessa ação conjunta, como jamais abriu mão de que o monopólio da segurança dos curdos na Síria ficasse sob responsabilidade das YPG (International Crisis Group, 2013).

O regime sírio, por sua vez, focado na supressão da revolta que gradualmente se espalhava pelo país, deu pouca atenção ao norte, onde os grupos curdos, apesar de protestarem contra Damasco, evitavam se engajar em ações mais radicais (Barfi, 2016). Tensões entre os curdos e a Síria só se tornaram mais visíveis em maio de 2012, quando manifestantes derrubaram cartazes e propagandas de Bashar al-Assad nas cidades do nordeste do país. O grande avanço do PYD 
ocorreu, entretanto, em julho de 2012, quando as YPG tomaram as cidades de al-Hasakah, al-Qamishli, Kobane e Afrin. As forças do regime demonstraram pouca resistência e desde então o governo Assad retirou a maior parte de suas tropas do norte do país (Barfi, 2016; International Crisis Group, 2013).

As YPG, representando os interesses do PYD, tomaram os prédios governamentais, bem como as estações de gás e petróleo, de modo a permitir a manutenção dos serviços públicos (International Crisis Group, 2013). Esses grupos também passaram a funcionar como o exército da região curda, controlando as fronteiras das áreas administradas pelo PYD, a fronteira com o Curdistão iraquiano e parte da fronteira com a Turquia. Criaram-se também novas unidades de polícia, responsáveis pelos checkpoints urbanos, em estradas e rodovias, e por fornecer segurança aos edifícios públicos (Paasche, 2015).

Desde o momento em que o governo turco se envolveu no conflito sírio, apoiando a oposição militar, Assad optou pela retirada das forças armadas da maior parte do território curdo por saber que um eventual governo nessa região se tornaria um contrapeso à ação turca. Assim como Hafez al-Assad fizera com o PKK, ao longo dos anos 1980 e 1990, Assad instrumentalizou a causa curda contra Ancara (An invigorated..., 2015).

Ainda que o governo turco tenha mantido sua postura de apoio à oposição contra Assad, surgiu uma nova preocupação em como conter a difusão dos ideais do PYD e evitar, sobretudo, que a autonomia do grupo possibilitasse a instalação de bases do PKK na Síria, o que facilitaria possíveis ataques à Turquia (Gunter, 2015). Em julho de 2012, Erdo an alegou que Assad propositalmente entregara o controle das províncias do norte ao PYD, visto que o regime jamais tomou qualquer ação para tentar recuperá-las, e também afirmou que a Turquia possuía o direito inalienável de intervir militarmente no país caso o PKK estabelecesse bases no território sírio (International Crisis Group, 2013). 


\section{O surgimento de Rojava: a expansão territorial curda e a batalha contra $0 \mathrm{EI}$}

Com a constituição de um governo no norte do país, em julho de 2012, o PYD passou a empreender um esforço de expandir seu controle territorial e consolidar um novo tipo de experimento político, tendo como fundamento teórico as ideias de Öcalan: o confederalismo democrático. Diversos encontros foram realizados durante o ano de 2013, culminando em uma conferência, no dia 12 de novembro, com a participação de mais de 35 organizações diferentes, incluindo as diversas etnias da região, como curdos, árabes, assírios e yazidis. Na ocasião, declarou-se a formação de uma assembleia de sessenta delegados a fim de elaborar uma carta em moldes constitucionais com representantes das três regiões curdas do norte sírio - Afrin, Kobane e Jazira (Hasakah) (Kurdistan National Congress, 2014). Em janeiro de 2014, seguindo os trabalhos realizados pela assembleia constituinte, os curdos declararam oficialmente sua autonomia, proclamando a criação da região de Rojava, composta pelos três cantões. A federação seria baseada em uma gestão descentralizada, no secularismo e na igualdade de gênero (Kurdistan National Congress, 2014).

A experiência de Rojava também enfrentou grupos islâmicos radicais. Já em outubro de 2013, as YPG expulsaram a al-Nusra (Frente de Suporte para o Povo da Síria, organização jihadista) das áreas ao redor da cidade de al-Hasakah (Gunter, 2015). Mas foi quando se deu o combate ao EI, em 2014, que a situação de Rojava passou por uma inflexão.

Com a ascensão do EI, que tomou as cidades de Raqqa, na Síria, e Mosul, no Iraque, os Estados Unidos, que até então apoiavam o grupo com armas e suprimentos, passaram a considerá-lo inimigo (Cockburn, 2015). A administração Obama, no entanto, não estava disposta a enviar forças terrestres convencionais para entrar em combate direto contra o EI, optando por ataques aéreos e a incentivar quaisquer grupos que estivessem dispostos a enfrentar os extremistas islâmicos em terra (Cockburn, 2015). 
Foi nesse contexto que os Estados Unidos perceberam no PYD um aliado em potencial e uma das forças terrestres mais efetivas na luta contra o EI. Além disso, a própria capital do EI, Raqqa, se localiza nas proximidades de áreas curdas (Gunter, 2015). A crescente parceria entre Washington e as forças curdas se intensificou, materializando-se a partir de setembro de 2014, quando os EUA expandiram as operações da coalizão ocidental no apoio às unidades curdas como decorrência do cerco do EI à cidade síria de Kobane, na fronteira com a Turquia (Gunter, 2015).

A defesa bem-sucedida de Kobane contra o EI, entre 2014 e 2015, demonstrou a importância militar dos curdos e, desde então, os Estados Unidos passaram a prover os curdos sírios com apoio militar, sobretudo em relação ao compartilhamento de inteligência na identificação de alvos estratégicos (Barfi, 2016). Diante do sucesso das YPG, a oposição curda síria, expressa pelo CNC e com apoio do GRC de Barzani, pouco pôde fazer para se impor no cenário político de Rojava, ficando cada vez mais nas sombras do PYD (Lowe, 2016).

Além disso, depois da vitória em Kobane, as YPG empreenderam novas campanhas militares pelo norte da Síria, conseguindo, entre maio e julho de 2015, tomar uma série de cidades. Esse sucesso militar permitiu que dois cantões, Kobane e Jazira, antes separados fisicamente pela presença de grupos extremistas como o EI, fossem unificados, criando uma faixa contínua de território controlado pelo PYD na fronteira turca (Lowe, 2016).

Desde que concretizou a vitória sobre o EI, em Kobane, e sua expansão territorial em 2015, o PYD construiu uma narrativa que enfatizava o esforço curdo como uma "resistência heroica" pela sobrevivência de seu povo contra extremistas islâmicos. Em um Oriente Médio cada vez mais tomado por ações de extremismo, o PYD procurou constituir-se como uma alternativa democrática, popular 
e secular, tendo como modelo o autogoverno de Rojava (Lowe, 2016).

Para o governo turco, essa articulação consolidou uma de suas grandes preocupações: os curdos na Síria demonstravam força ao combater o EI e, assim, recebiam apoio político e material de Washington e da Organização do Tratado do Atlântico Norte (Otan). Temia-se que, como consequência, a derrota do EI facilitasse o reconhecimento por parte dos Estados Unidos do PYD e seus ganhos territoriais.

Apesar de as unidades curdas serem uma força importante no combate ao EI, a Otan não poderia deixar de levar em consideração as demandas da Turquia, seu membro, em relação ao PYD. Os Estados Unidos passaram, assim, a criticar o unilateralismo do PYD em relação aos demais grupos políticos curdos da Síria, além de reafirmar que as linhas de fronteira estatais deveriam ser mantidas. Uma das táticas empregadas por Washington para poder cana230 lizar apoio às unidades curdas foi pressionar o PYD a formar uma força conjunta com outros grupos árabes sunitas (Barfi, 2016). Tal ação desdobrou-se em outubro de 2015 na criação das Forças Democráticas Sírias (FDS), uma coalizão de combatentes envolvendo tanto grupos árabes quanto as YPG - embora estas permanecessem a força dominante em número absoluto e relativo. A administração Obama seguiu apoiando as FDS durante o ano de 2016, apontando o grupo como uma das possíveis forças a se envolverem na eventual operação para tomar Raqqa, a capital do EI (Barfi, 2016).

A conquista pelas FDS lideradas pelas YPG da cidade síria de Manbij, localizada a oeste do rio Eufrates, em agosto de 2016, que estava sob controle do EI, foi vista como uma ameaça pelo governo da Turquia, o qual já havia afirmado anteriormente que não aceitaria que as forças curdas cruzassem o rio Eufrates. Isso porque tal avanço poderia significar uma continuada investida a fim de tentar unificar os cantões do leste com o cantão restante no oeste, Afrin, criando uma 
zona unificada curda no norte sírio. Portanto, a tomada de Manbij tornou-se fator decisivo para a primeira intervenção militar direta da Turquia na Síria (Dal, 2017).

\section{Rojava: ideias políticas e gestão de território}

Além de ser um enclave curdo no Oriente Médio, reavivando a utopia de se criar uma região curda autônoma, Rojava chamou a atenção internacional também por ser um laboratório para as ideias de democracia apregoadas pelo líder curdo, Öcalan. Uma das questões centrais dessa proposta é a superação do modelo de Estado-nação, que seria, segundo Öcalan, uma das principais fontes de divisões sociopolíticas no Oriente Médio - principalmente em relação a minorias étnicas que têm problemas relacionados ao reconhecimento por governos nacionais (Kurdistan National Congress, 2014).

Mas Öcalan advertia que não se deveria negar o Estado sírio em sua totalidade, desrespeitando as fronteiras reconhecidas, sem dúvida uma diferença marcante em relação às posturas anteriores do PKK quando pregava claramente a criação de um Estado curdo completamente independente (Kurdistan National Congress, 2014). O objetivo principal seria o de repensar as estruturas e as instituições estatais existentes, buscando novas formas de organização política não mais baseadas em critérios étnicos ou religiosos e que trabalhassem em conjunto com a ideia de autogoverno de modo a equilibrar democracia participativa e democracia representativa (Kurdistan National Congress, 2014).

A viabilidade de Rojava como uma entidade autônoma e sustentável, no longo prazo, envolveria, no entanto, outros fatores além das questões políticas internas, como as relações com os Estados vizinhos e fatores estruturais, como recursos naturais, água e petróleo (Balanche, 2016).

A expansão territorial ocorrida depois das vitórias sobre o EI em Kobane e Tell Abyad, ligando os cantões do leste, garantiu ao PYD uma região com mais recursos e população 
mais numerosa a ser governada. Nesse sentido, à medida que Rojava se expandia, a população deixava de ser homogeneamente curda, tornando-se mais heterogênea em termos étnicos (Balanche, 2016). Atualmente, nos cantões orientais de Jazira e Kobane, a população curda está em torno de 55\%. Em Afrin, por outro lado, no cantão mais afastado, a população é majoritariamente curda. Entretanto, cabe destacar que os mapas oficiais do PYD indicam que o cantão de Afrin poderia incorporar, eventualmente, outras cidades, o que diminuiria a porcentagem de curdos para apenas 30\% (Balanche, 2016).

Pode-se dizer que, após o início da guerra civil na Síria, a escassez de água tem se tornado o principal problema enfrentado por Rojava, porque a agricultura é a principal fonte de renda da população local. O alto consumo de água no lado turco da fronteira reduziu consideravelmente o abastecimento no norte da Síria, e o regime de Assad não fez nenhum esforço para resolver o problema. Nos anos que 232 antecederam a guerra, a seca e o alto preço do combustível para irrigação causaram uma redução significativa nas áreas cultivadas, tendo como consequência ondas migratórias curdas para grandes centros urbanos, diferentemente do que aconteceu no Vale do Eufrates, onde os agricultores receberam água subsidiada e abundante devido aos projetos de irrigação do Estado. O controle curdo da Barragem de Tishrin, no Eufrates, poderia apresentar novas perspectivas para o desenvolvimento da irrigação a oeste de Rojava, que também sofria de escassez. No entanto, tais esforços provavelmente criariam problemas com os agricultores árabes que vivem na parte mais baixa do rio (Balanche, 2016).

No que se refere aos recursos petrolíferos, cabe mencionar que, antes do início da guerra, os campos de al-Malikiyah e al-Shadadi, sob controle curdo no cantão de Jazira, produziam cerca de um terço de todo o petróleo bruto do país. Depois de iniciado o conflito, esses números caíram, dada a falta de manutenção de oleodutos, mas sobretudo pela dificuldade 
de exportar o combustível. Por conta do não reconhecimento de Rojava pelo governo em Ancara, é praticamente impossível passar pelo território turco. Se tentasse, por outro lado, exportar pelo antigo oleoduto que leva ao terminal de Banias, na costa Mediterrânea, os curdos teriam de vender ao governo sírio, visto que o cantão de Afrin não possui saída para o mar. Nesse caso, Damasco poderia ou não reconhecer a autonomia curda ou ainda não querer pagar por um recurso que está dentro de seu próprio território. Caso tente exportar via Iraque, seria necessário um entendimento com o GRC de Barzani, que, entretanto, tem problemas com o PYD (Balanche, 2016).

O papel do território na coalizão contra o EI que funcionou, inicialmente, de modo favorável aos curdos sírios em seu embate militar, tornou-se, ao mesmo tempo, sua limitação quando teve início a fase de realizar propriamente seu experimento social.

\section{Desdobramentos regionais: a Turquia diante da expansão curda}

Como vimos, a primeira reação do governo turco à obtenção de autonomia por parte do PYD foi incentivar que Barzani, por intermédio do GRC, buscasse influenciar o rumo dos grupos curdos na Síria, da mesma forma que a Turquia já vinha fazendo em relação ao Curdistão iraquiano. Entretanto, os esforços de mediação de Barzani entre o PYD e o CNC não tiveram sucesso e o GRC não conseguiu afastar o principal grupo de curdos da Síria do PKK. Diante do insucesso de Barzani, o governo turco tentou, em vão, em julho de 2013, dissuadir o PYD de declarar Rojava como região autônoma, exigindo: que não cooperassem com o regime de Assad; que não formassem uma entidade política com bases étnicas ou religiosas; e que não se engajassem em atividades que colocariam em risco a segurança da fronteira turca (Gunter, 2015).

Entre março e abril de 2014, o comandante das YPG passou a conclamar os curdos da Turquia a colaborar para o esforço de 
combate contra grupos radicais islâmicos. Ao ver as YPG flertarem com a ideia de um movimento curdo transfronteiriço, o governo turco passou a preocupar-se ainda mais com Rojava (Gunter, 2015). Sua resposta foi a de manter o apoio dado à oposição síria, que incluía grupos islâmicos mais radicais que enfrentavam as YPG. Essa anuência turca para a proliferação de jihadistas foi reconhecida pelo próprio vice-presidente dos EUA, Joe Biden, em 2014 (Cockburn, 2015; Gunter, 2015).

Foi, porém, com a ascensão do EI que a Turquia percebeu que a situação estava se agravando, haja vista que o combate ao grupo fez com que os curdos sírios se aproximassem dos EUA, principalmente depois do cerco de Kobane em 2014 (Cockburn, 2015). O governo turco declarou que não poderia participar da coalizão das potências ocidentais, pois desde junho de 2014, quando o EI havia tomado Mosul, diplomatas turcos estavam sendo mantidos reféns pelo grupo. Entretanto, mesmo com a libertação dos reféns, em setembro do mesmo ano, a Turquia continuou a não tomar parte na coalizão (Cockburn, 2015).

Durante a decisiva batalha de Kobane, Erdo an não apenas declarou que o PKK era semelhante ao EI (Park, 2015), mas também que a Turquia só apoiaria uma ação militar se os Estados Unidos sustentassem a ideia da criação de uma "zona tampão" dentro do território sírio nos limites da fronteira turca, a qual serviria para garantir que nem os curdos nem o EI ali permanecessem (Kanat e Ustun, 2015).

$\mathrm{O}$ atrito entre os aliados ocidentais e o governo turco cresceu na medida em que divergiam quanto à principal ameaça a ser combatida na Síria: para Ancara, preocupava o poder crescente dos curdos, e, para os aliados, a expansão de forças consideradas extremistas (Cockburn, 2015; Park, 2015). Essa diferença de percepções de ameaças do governo turco e dos membros da Otan gerou grandes tensões na relação entre Turquia e seus aliados.

A situação veio a mudar somente em julho de 2015, quando a Turquia assumiu uma nova tática: enfrentar simultaneamente 
o PKK e o EI. Tal mudança, entretanto, pareceu não ter sido fruto direto da tensão com as potências ocidentais, mas sim de uma derrota sofrida pelo Partido da Justiça e Desenvolvimento (AKP, na sigla original) nas eleições turcas em junho de 2015 (Yavuz e Öscan, 2015). Pela primeira vez desde que chegara ao poder em 2002, o governo do AKP perdeu a maioria parlamentar, conseguindo 40,9\% dos votos totais. Além disso, também pela primeira vez, o Partido Democrático dos Povos (HDP, na sigla original), ligado ao movimento curdo turco, conseguiu passar da barreira de $10 \%$ de votos necessários para entrar no parlamento, recebendo 13,1\% (Yavuz e Öscan, 2015). A eleição representou uma derrota significativa para Erdo an e o AKP, sobretudo depois de Kobane. Não apenas os curdos na Síria haviam pleiteado aos EUA um espaço legítimo na luta contra o EI como também o partido curdo turco chegara ao parlamento.

Um governo de coalizão foi negado por parte do AKP e, portanto, novas eleições tiveram de ser convocadas para novembro de 2015. Para vencer o novo pleito e consolidar a posição doméstica, o governo AKP optou por uma nova estratégia, empregando uma abordagem mais nacionalista e assertiva. Para tanto, colocou-se definitivamente contra o EI, mas também retomou o combate ao PKK internamente (Yavuz e Öscan, 2015). Menos de um mês após a derrota do governo na eleição, a Turquia finalmente cedia à pressão dos Estados Unidos, juntando-se à coalizão contra o EI. Paralelamente, decretou o fim do cessar-fogo que tinha sido estabelecido com o PKK desde 2013, retomando a guerra contra o grupo (An invigorated..., 2015).

A postura do HDP no parlamento acabou facilitando a estratégia do AKP. Desde o fim do cerco em Kobane em 2014, o PKK já havia reiniciado alguns atentados contra alvos policiais e de lideranças curdas contrárias ao grupo no sudeste da Turquia. Após sua vitória, o HDP, entretanto, foi reticente e recusou-se a repudiar as ações violentas cada vez mais recorrentes realizadas pelo PKK em território turco (Yavuz e Öscan, 2015). Em 
meio ao aumento do clima de insegurança, o governo do AKP alardeava a piora na situação do país, culpando principalmente o HDP por não conseguir controlar o PKK, taxando-o como "braço político do terrorismo" (Yavuz e Öscan, 2015).

Quando ocorreram as eleições, em novembro de 2015, a Turquia se encontrava marcada por uma dupla guerra contra o EI e o PKK. Os grupos nacionalistas, que antes votavam no Partido de Ação Nacionalista (MHP, na sigla original), migraram para o AKP, bem como os votos de grupos liberais e de esquerda que, tendo antes votado no HDP, passaram a desconfiar de sua ligação com o PKK (Yavuz e Öscan 2015). Como resultado, o AKP obteve novamente a maioria, 49,49\%, e o HDP caiu para apenas 10,75\% dos votos (Yavuz e Öscan, 2015).

A vitória do AKP nas eleições indicou que havia uma percepção predominante entre os turcos de que os curdos eram a principal ameaça ao Estado. Nesse sentido, o governo turco tomou duas iniciativas: primeiro, reivindicou, 236 na Otan, a implementação de uma "zona tampão" na Síria a fim de agrupar a oposição contra Assad e reassentar os refugiados do conflito; depois, empreendeu ação militar terrestre em solo sírio para frear os avanços do PYD.

As forças armadas turcas seriam as responsáveis pela criação e manutenção da zona, desde que a Otan as apoiasse com a imposição de uma zona de exclusão aérea sobre o território (Bernard, Gordon e Schmitt, 2015). A despeito da explicação oficial, a escolha do traçado para a imposição dessa área, entre Afrin e Kobane, mostra que também serviria ao propósito de conter a expansão curda, uma vez que a presença de forças turcas seria um empecilho concreto para o surgimento de uma região curda unificada.

O plano turco, entretanto, não recebeu apoio da Otan, visto que essa também teria que tomar parte na aplicação da zona aérea, o que poderia ser visto pela Rússia como uma demonstração de força das potências ocidentais. Além disso, em setembro de 2015, menos de dois meses após a entrada 
da Turquia na coalizão e de a ideia da zona tampão voltar a ser debatida, o governo russo, aliado de Assad, iniciou ataques aéreos na Síria - o que poderia envolver a Otan em sérios problemas com Moscou (Mufti, 2017).

Apesar da não aplicação da zona tampão e do envolvimento russo mais direto no conflito sírio, o governo turco manteve a mesma estratégia e, em 24 de agosto de 2016, em resposta aos avanços do PYD nesse território, realizou sua primeira intervenção militar terrestre na Síria, a Operação Escudo do Eufrates. Utilizando forças especiais e veículos blindados, com o auxílio de unidades do Exército Sírio Livre (ESL), o governo turco expulsou unidades de combate do EI da cidade síria de Jarabulus, na fronteira da Turquia. Com a operação militar, o grupo radical islâmico perdeu a última cidade que ainda estava sob seu controle ao longo da fronteira turca.

A estratégia de combate ao EI empregada pela Turquia estava, mais uma vez, diretamente ligada às suas posições em relação ao PYD. Jarabulus estava dominada pelo EI há muito tempo, mas a Operação Escudo do Eufrates ocorreu somente depois de o PYD atravessar o rio Eufrates e tomar a cidade síria de Manbij (Dicle, 2016; Gurcan, 2016). O governo AKP considerava a presença do PYD a leste do Eufrates como a linha que não poderia ser atravessada pelos curdos sírios. Nesse sentido, a operação foi uma ação militar não apenas para expulsar o EI da fronteira turca, mas também para dissuadir as unidades curdas de se expandir (Gurcan, 2016).

A operação turca avançou até a tomada de A'zaz, no início de 2015, criando uma barreira concreta entre os cantões curdos e Afrin, no oeste, e Kobane, no leste (Gurcan, 2016). Após o controle das primeiras cidades no norte sírio, a Operação se moveu para capturar a cidade de al-Bab, então ainda sob controle do EI, localizada entre os cantões de Kobane e Afrin, lugar estratégico para que a Turquia prevenisse a conexão curda. Paralelamente a isso, em 22 de novembro de 2016, uma corte turca emitiu um mandado de prisão contra Salih Muslim, o líder do PYD (Mufti, 2017). 
Os acontecimentos do ano de 2017 apenas corroboraram a crescente interação entre a questão curda e a política externa da Turquia. O grande fator decisivo nesse ano foi a decisão do governo Trump de armar os curdos sírios a fim de utilizar essas forças na investida final contra a capital do EI, Raqqa, dada sua proximidade com os cantões curdos de Rojava. Com o novo armamento, a operação contra Raqqa iniciou-se em junho e foi encerrada em outubro de 2017, com a expulsão do grupo radical islâmico de lá (Kayaoglu, 2017). Conforme a Figura 1, resulta que, naquele mês, as forças curdas já haviam consolidado uma expansão bastante significativa na Síria e seu poder de barganha aumentava cada vez mais.

Figura 1

Controle territorial na guerra Síria, em outubro de 2017

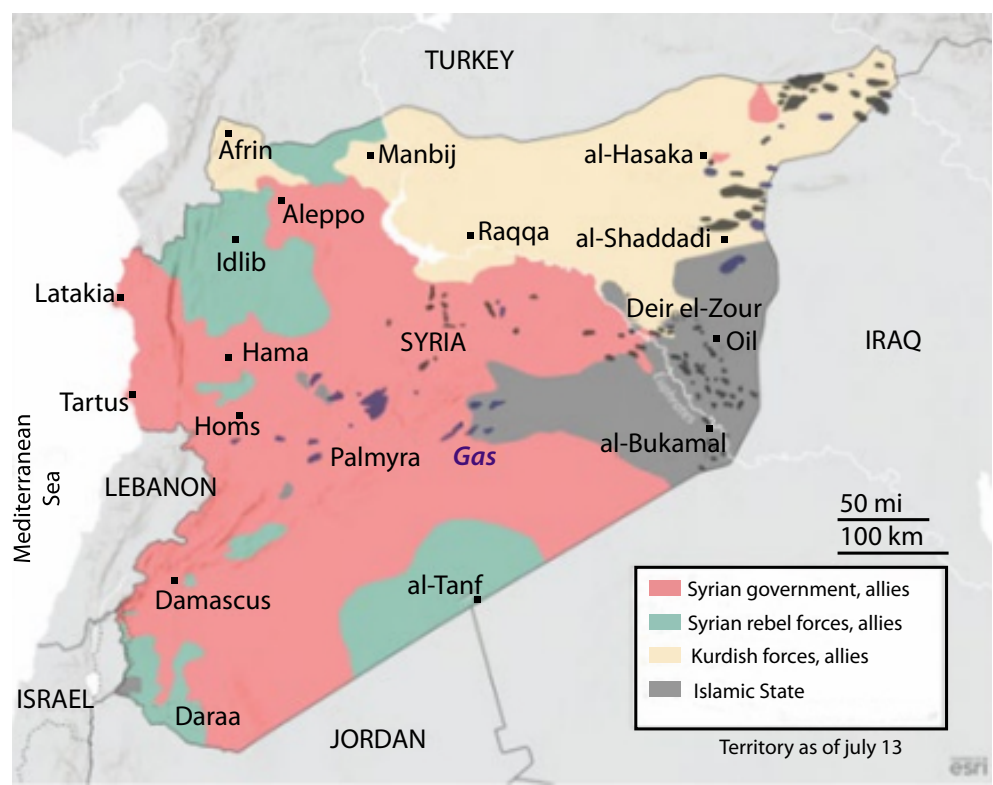

Nota: Em rosa, governo sírio e aliados; em verde, rebeldes sírios e aliados; em amarelo, forças curdas; em cinza, EI.

Fonte: Syria... (2017). 
O governo turco revidou, no início de 2018, aos ganhos curdos depois da tomada de Raqqa. Já que as forças do PYD haviam consolidado um território expressivo, do nordeste sírio até a cidade de Raqqa (Figura 1), o AKP optou por iniciar uma nova operação militar no cantão curdo de Afrin, mais exposto e ainda desconectado do resto do território curdo. A Operação Ramo de Oliveira teve início no dia 20 de janeiro de 2018 e se encerrou no dia 24 de março do mesmo ano após a tomada da cidade de Afrin, que saiu do controle do PYD (Karam, 2018). A Figura 2 mostra a configuração política do território sírio com os recentes avanços turcos no noroeste em relação ao território curdo consolidado no leste e nordeste.

\section{Figura 2}

Controle territorial na guerra Síria, em maio de 2018

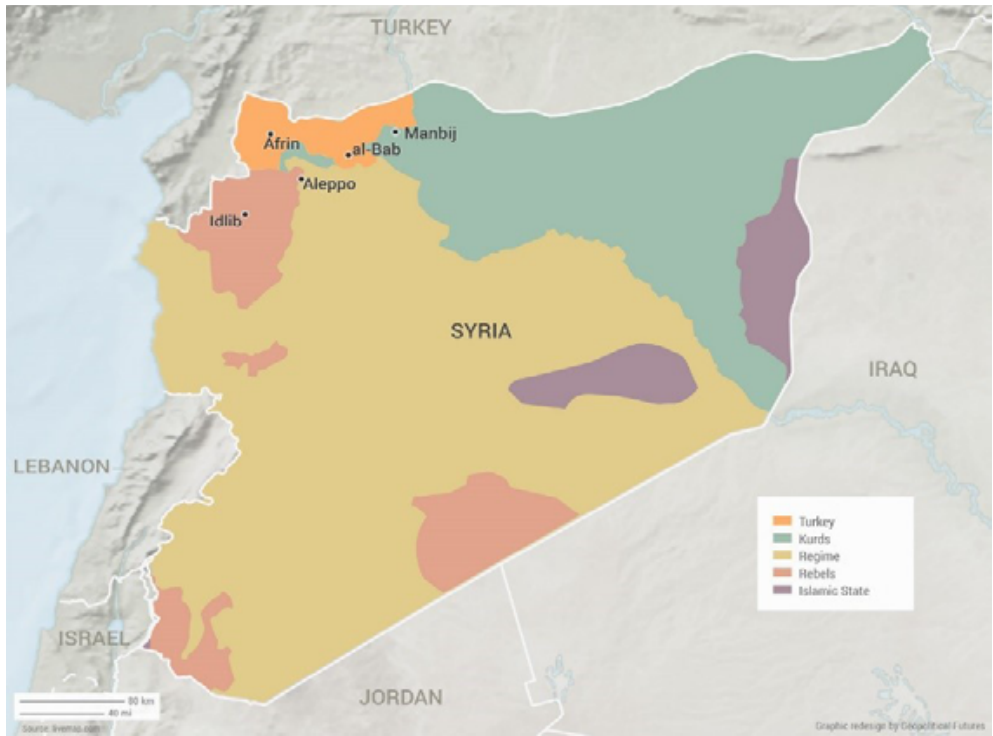

Nota: Em laranja, Turquia; em verde, curdos; em amarelo, regime sírio; em rosa, forças rebeldes da Síria; em roxo, EI.

Fonte: Gauging... (2018). 


\section{Conclusão}

Como pudemos constatar, o movimento curdo não é único, e muito menos homogêneo. O CNC foi formado para se contrapor ao PYD e representou uma ingerência direta do movimento curdo iraquiano sobre os grupos curdos sírios. Na verdade, a divisão do movimento curdo sírio reflete divergências já existentes no movimento curdo de modo geral, principalmente entre o PKK e o GRC. Assim como o CNC foi apoiado pelo GRC, o PYD e as YPG estão ligadas ao PKK turco.

Não apenas o PYD foi formado como braço do PKK na Síria depois de este grupo ter sido expulso do território no final dos anos 1990, como também grande parte das YPG treinaram ao lado dos guerrilheiros do PKK no Iraque. Nesse sentido, há uma forte ligação ideológica entre os dois grupos, o que é reforçado pelo fato de o PYD se inspirar nos escritos de Öcalan. Porém, cabe destacar que, a despeito dos 240 laços existentes entre o PKK e o PYD, o grupo sírio é uma entidade diferente e busca se distanciar do grupo turco, principalmente ao afirmar sua autonomia sobre um determinado território.

Por ter laços com o PKK e ter conseguido certa autonomia dentro da Síria, no contexto da guerra civil, a expansão curda fez com que o governo turco ficasse em alerta, já que temia, por um lado, o transbordamento das mesmas ideias autonomistas para curdos que moram na Turquia e, por outro, que o território controlado pelo PYD se tornasse uma base logística para o PKK.

Inicialmente, o governo turco mostrou cautela, preferindo buscar influenciar o PYD com a mediação de Barzani, líder do GRC, e do GNC. No entanto, na medida em que o PYD se recusou a ceder aos outros grupos e se tornou uma das principais forças terrestres de combate ao EI, aproximando-se dos Estados Unidos, o governo turco passou a ser mais assertivo. A Turquia recusou-se, incialmente, a 
participar da coalizão montada pelos Estados Unidos, em 2014, e apenas se engajou nessa luta, ao mesmo tempo que declarava guerra ao PKK, após o resultado das eleições de 2015, quando assumiu novo tom nacionalista de enfrentamento. Desde então, o governo turco pleiteou a imposição de uma zona tampão no norte sírio - o que foi efetivado pelas próprias forças turcas e seus parceiros locais com a Operação Escudo do Eufrates, em agosto de 2016, quando as YPG tomaram Manbij.

As teorias mais amplamente difundidas sobre identidades sociais, etnias e nacionalismo são incapazes de explicar as constantes mudanças e redefinições envolvendo os grupos políticos. É importante buscar compreender por que um grupo de curdos tem um status favorecido em relação a outros, ou, ainda, por que grupos nacionalistas curdos hesitariam em trabalhar uns com os outros e ter relações tão divergentes com um Estado vizinho. Se fossem levadas em consideração apenas questões de identidade e de nacionalismo, como base para o irredentismo, os curdos iraquianos seriam uma ameaça muito maior para a Turquia devido ao tamanho comparativo de sua população em seus territórios de origem. Além disso, se avaliarmos o comportamento da Turquia em relação aos territórios curdos no Iraque e na Síria, segundo a perspectiva das teorias neorrealistas nas relações internacionais, também chegaremos a um impasse, pois se o poder é o critério para se configurar como maior ameaça, o GRC deveria ser a maior preocupação da Turquia, em vez do PYD (Wuthrich, 2018).

É inegável que o movimento curdo na Síria conquistou diversas vitórias tanto em termos políticos, ao implementar um governo democrático, quanto nos combates militares. Entretanto, sua sobrevivência em Rojava depende de fatores de ordem política e econômica. O movimento encontra dificuldades para vender petróleo, sua principal fonte de receita, visto ser necessário dialogar com o GRC, a Turquia 
ou o governo em Damasco, o que remete, por sua vez, às relações externas. Isso é, o futuro de Rojava depende, de certa forma, do posicionamento dos Estados Unidos e da Turquia em relação ao poderio militar que possuem. Enquanto é improvável que Washington entre no conflito apenas pela questão curda, o governo turco, por sua vez, está decidido a não permitir sob nenhuma condição a existência de uma região curda unificada.

Embora não seja possível desconsiderar as variáveis de capacidades concretas como recursos para projetar poder, também é preciso levar em consideração que as ideologias possuem um papel fundamental na ação dos Estados e das organizações políticas. A percepção da ameaça que outros grupos possam representar aos interesses domésticos e internacionais de um Estado é sempre filtrada por uma lente ideológica que baliza as relações de afinidade ou antagonismo, influenciando a determinação de quem é conside242 rado "amigo" e "inimigo".

Um fator crítico, subjacente às relações extracomunais e entre comunidades curdas, são as percepções de similaridade ou divergência da perspectiva ideológica das lideranças das organizações nacionalistas curdas, bem como seus relacionamentos com os Estados vizinhos. No que se refere às relações interestatais e às rivalidades entre as organizações, aproximações e distanciamentos ideológicos se constituem critérios mais precisos para avaliar as interações entre as organizações curdas do que as alternativas teóricas construídas exclusivamente sobre análises de identidades étnicas (Brubaker, 2004).

O caráter fragmentado da identidade política curda, embora certamente reflita realidades provenientes da complexidade das respectivas sociedades da qual fazem parte, também deve ser levado em consideração na análise das relações transnacionais dessas organizações. Os Estados que contêm população curda tentam deliberadamente aumentar as divisões entre as organizações que os representam, 
enquanto estas, na busca do apoio de um desses Estados, na maior parte reforçam e não transcendem o caráter fragmentado da identidade política curda. Vale ressaltar que o PKK, uma das organizações curdas mais bem-sucedidas e influentes na história dos movimentos nacionalistas curdos, abandonou sua demanda por independência e seu discurso político de base marxista por reivindicações centradas em direitos linguísticos e culturais para seu povo dentro dos limites da Turquia desde 1993.

Em outras palavras, as características que qualificam a identidade curda existem e são reconhecidas entre seus membros há muito tempo, mas a capacidade de constituir grupos organizados politicamente entre essas populações tem variado, embora essa tendência tenha aumentado imensamente nas últimas décadas. Além disso, o agrupamento político requer esforço e, portanto, é necessário entender como se constitui um grupo a partir de um projeto político, rastreando as formas sociais, culturais e políticas pelas quais as categorias identitárias são elementos importantes para gerar grupos.

\section{Reginaldo Mattar Nasser}

é professor do departamento de Relações Internacionais da Pontifícia Universidade Católica de São Paulo (PUC-SP) e do Programa de Pós-Graduação San Tiago Dantas (Unesp-Unicamp-PUC-SP). Pesquisador do Instituto Nacional de Ciência e Tecnologia para Estudos sobre os Estados Unidos (Ineu) e líder do Grupo de Estudos sobre Conflitos Internacionais (Geci), do Conselho Nacional de Desenvolvimento Científico e Tecnológico (CNPq). Foi organizador e autor de capítulos nos livros Novas perspectivas sobre os conflitos internacionais e Conflitos internacionais em múltiplas dimensões, ambos publicados pela Editora Unesp. Coorganizou livros com André de Mello e Souza e Rodrigo Moraes e escreveu capítulos do livro Do 11 de setembro de 2001 à guerra ao terror: reflexões sobre o terrorismo no século XXI, 
publicado pelo Ipea. Tem se dedicado a pesquisar temas relacionados a violência organizada nas relações internacionais, em geral, e em particular no Oriente Médio.

\section{Willian Moraes Roberto}

é mestre em relações internacionais pelo Programa de PósGraduação San Tiago Dantas (Unesp-Unicamp-PUC-SP) e pesquisador do Instituto Nacional de Ciência e Tecnologia para Estudos sobre os Estados Unidos (Ineu) e do Grupo de Estudos sobre Conflitos Internacionais (Geci), do Conselho Nacional de Desenvolvimento Científico e Tecnológico (CNPq).

\section{Bibliografia}

AN INVIGORATED Turkey lashes out. 2015. Stratfor, 28 jul. 2015. Reflections.

Disponível em: https://bit.ly/2GEISO4. Acesso em: 22 fev. 2019.

BALANCHE, Fabrice. 2016. Rojava's sustainability and the PKK's regional strategy. The Washington Institute, 24 ago. 2016. Disponível em: https:/ /

BARFI, Barak. 2016. Ascent of the PYD and the SDF. Research Notes, n. 32.

Disponível em: https:/ / bit.ly/2SjbldF. Acesso em: 22 fev. 2019.

BARNARD, Anne; GORDON, Michael R.; SCHMITT, Eric. 2015. Turkey and U.S. plan to create Syria 'safe zone' free of ISIS. The New York Times, 27 jul. 2015. Disponível em: https://nyti.ms/2SjbTAf. Acesso em: 22 fev. 2019.

BRUBAKER, Rogers. 2004. Ethnicity without groups. Cambridge, MA: Harvard University Press.

CAPITALIZING on the Kurds. 2016. Stratfor, 17 fev. 2016. Assessments. Disponível em: https:/ /bit.ly/2E59XX7. Acesso em: 22 fev. 2019.

COCKBURN, Patrick. 2015. The rise of Islamic State: ISIS and the new Sunni revolution. Londres: Verso.

DAL, Emel Parlar. 2017. Impact of the transnationalization of the Syrian civil war on Turkey: conflict spillover cases of ISIS and PYD-YPG/PKK. Cambridge Review of International Affairs, v. 29, n. 4, pp. 1396-1420.

DEYOUNG, Karen. 2016. Biden warns Kurds not to seek separate enclave on Turkish-Syrian border. The Washington Post, 24 ago. 2016. Disponível em: https://wapo.st/2bC5nV3. Acesso em: 22 fev. 2019.

DICLE, Amed. 2016. Will Turkey's Jarablus win lead to showdown with Kurds? Al-Monitor, 25 ago. 2016. Disponível em: https://bit. ly/2GCnIQR. Acesso em: 22 fev. 2019. 
GAUGING the strength of the Turkish military. 2018. Geopolitical Futures, 10 maio 2018. Disponível em: https:/ /bit.ly/2U0hblO. Acesso em: 22 fev. 2019.

Gunter, Michael M. 2008. The Kurds ascending: the evolving solution to the Kurdish problem in Iraq and Turkey. Basingstoke: Palgrave Macmillan.

GUNTER, Michael M. 2015. Iraq, Syria, ISIS and the Kurds: geostrategic concerns for the U.S. and Turkey. Middle East Policy, v. 22, n. 1.

GURCAN, Metin. 2016. What's Turkey really up to in Syria? Al-Monitor, 25 ago. 2016. Disponível em: https:/ / bit.ly/2T38biP. Acesso em: 22 fev. 2019.

HAAS, Mark. 2005. The ideological origins of great power politics, 1789-1989. Ithaca: Cornell University.

HALHALLI, Bekir. 2015a. Turkey's Rojava Dilemma. Research Turkey, v. 4, n. 3, pp. 94-100. Disponível em: http://bit.ly/2TgjAYi. Acesso em: 22 fev. 2019.

HALHALLI, Bekir. 2015b. Turkish policy towards the Kurds in Syria. IDEAZ, v. 13, pp. 39-58.

HALHALLI, Bekir. 2018. Kurdish political parties in Syria: past struggles and future expectations. In: TUGDAR, Emel Elif; AL, Serhun (eds.). Comparative Kurdish politics in the Middle East. Londres: Palgrave Macmillan. pp. 27-53.

HALLIDAY, Fred. 2005. The Middle East in International Relations: power, politics and ideology. Cambridge: Cambridge University Press.

HOW TURKEY will change the war in Syria. 2015. Stratfor, 28 jul. 2015.

Graphics. Disponível em: https:/ /bit.ly/2U1IT1v. Acesso em: 22 fev. 2019.

HUNTINGTON, Samuel. 1996. O choque de civilizações. Rio de Janeiro: Ponto de Leitura.

INTERNATIONAL CRISIS GROUP. 2013. Syria's Kurds: a struggle within a struggle. Bruxelas: International Crisis Group. (Middle East Report n. 136). Disponível: https://bit.ly/2EpGubB. Acesso em: 22 fev. 2019.

KANAT, Kilic; USTUN, Kadir. 2015. U.S.-Turkey realignment on Syria. Middle East Policy, v. 22, n. 4, pp. 88-97.

KARAM, Zeina. 2018. AP explains: what's next after Turkey seizes Syria's Afrin. AP News, 19 mar. 2018. Disponível em: https://bit.ly/2VkB0or. Acesso em: 22 fev. 2019.

KAYAOGLU, Barin. 2017. Can US calm Turkish nerves over arming Syrian Kurds? Al-Monitor, 11 maio 2017. Disponível em: https:/ /bit. ly/2GIQzTs. Acesso em: 22 fev. 2019.

KHAZAN, Olga. 2012. Who's fighting whom in Syria? The Washington Post, 18 out. 2012. Disponível em: https://wapo.st/2BYu8Wz. Acesso em: 22 fev. 2019.

KURDISTAN NATIONAL CONGRESS. 2014. Canton based democratic autonomy of Rojava: a transformation process from dictatorship to democracy. Bruxelas: KNK. Disponível em: https://bit.ly/2EpiNQT. Acesso em: 22 fev. 2019. 
LEWIS, Martin W. 2014. Michael Izady's amazingly detailed map of ethnicity in Syria (and the Syrian Armenians). GeoCurrents, 26 out. 2014. Disponível em: https://bit.ly/2NkRUjF. Acesso em: 22 fev. 2019.

LOWE, Robert. 2016. Rojava at 4: examining the experiment in Western Kurdistan. Middle East Centre. Disponível em: https://bit.ly/2GEE636. Acesso em: 22 fev. 2019.

MUFTI, Malik. 2017. Turkey's choice. Insight Turkey, v. 19, n. 1, pp. 71-87. NATALI, Denise. 2005. The Kurds and the State: evolving national identity in Iraq, Turkey, and Iran. Syracuse: Syracuse University Press.

PAASCHE, Till F. 2015. Syrian and Iraqi Kurds: conflict and cooperation. Middle East Policy, v. 22, n. 1.

PARK, Bill. 2015. Turkey's isolated stance: an ally no more, or just the usual turbulence? International Affairs, v. 91, n. 3, pp. 581-600.

RETAKING Ramadi is only a small victory. 2015. Stratfor, 28 dez. 2015. Assessments. Disponível em: https://bit.ly/2NmKjkP. Acesso em: 22 fev. 2019.

ROBERTO, Willian Moraes. 2018. As mudanças na política externa contemporânea da Turquia: as respostas diante das revoltas árabes pós-2011. Dissertação de Mestrado em Relações Internacionais. São Paulo: Unesp: Unicamp: PUC-SP.

246 RUSSIA leaves Syria with loyalists on the offensive. 2016. Stratfor, 15 mar. 2016. Assessments. Disponível em: https://bit.ly/2SVrI5q. Acesso em: 22 fev. 2019.

SHAPIRO, Jacob. 2016. The Islamic State strikes back. Geopolitical Futures, 14 dez. 2016. Disponível em: https://bit.ly/2H2iPQt. Acesso em: 22 fev. 2019. SYRIA: U.S.-backed forces take Raqqa from the Islamic State. 2017.

Stratfor, 17 out. 2017. Snapshots. Disponível em: https://bit. ly/2TaLxop. Acesso em: 22 fev. 2019.

TEJEL, Jordi. 2009. Syria's Kurds: history, politics and society. New York: Routledge. THE KURDS' precarious balancing act in Syria. 2017. Strategic Comments, v. 23, n. 4, pp. v-vi.

WUTHRICH, F. Michael. 2018. Kurdish nationalist organizations, neighboring states, and "ideological distance". In: TUGDAR, Emel Elif; AL, Serhun (eds.). Comparative Kurdish politics in the Middle East. Londres: Palgrave Macmillan. pp. 85-112.

YAVUZ, M. Hakan; ÖZCAN, Nihat Ali. Turkish Democracy and the Kurdish Question. Middle East Policy, v. XXII, n. 4, 2015. 


\section{A QUESTÃO CURDA NA GUERRA DA SÍRIA: DINÂMICAS INTERNAS E IMPACTOS REGIONAIS}

\section{REGINALDO MATTAR}

\section{WILLIAM ROBERTO}

Resumo: As características que qualificam a identidade curda são reconhecidas entre seus membros há muito tempo, mas a capacidade de constituir grupos politicamente organizados entre essa população variou ao longo da história. Para compreender a complexidade da questão curda no Oriente Médio, é preciso analisar a forma pela qual eles se organizam politicamente, levando em consideração suas ideologias, particularidades do Estado em que se encontram, e, principalmente, as tensões políticas e disputas internas de seus movimentos. Além disso, é fundamental inserir a reivindicação de autonomia dos curdos no contexto da evolução da guerra civil na Síria de modo mais amplo, por ser esse um dos principais motivos do crescente envolvimento da Turquia e das grandes potências na região.

Palavras-chave: Curdos; Guerra Civil na Síria; Turquia; Oriente Médio.

\section{THE KURDISH QUESTION IN SYRIAN WAR: DOMESTIC DYNAMICS AND REGIONAL IMPACTS}

Abstract: The characteristics that qualify the Kurdish identity have long been recognized among its members, but the ability to form politically organized groups among them has varied throughout history. In order to understand the complexity of the Kurdish question in the Middle East, it is necessary to analyze the way in which they organize themselves politically, taking into account their ideologies, particularities of the State in which they find themselves, and, most of all, the political tensions and internal disputes of their movements. In addition to that, it is essential to insert Kurds' claim 
on autonomy in the context of the evolution of the civil war in Syria in a broader sense, as this is one of the main reasons for the growing involvement of Turkey and the great powers in the region.

Keywords: Kurdish; Syrian Civil War; Turkey; Middle East.

Recebido: 07/04/2018Ａprovado: 24/02/2019 